\title{
Power-Following Control Strategy of a Wheel-Drive Hydraulic Hybrid Vehicle
}

\author{
Tao Zhang - Qiang Wang - Xiao-Hui He* - Si-Sheng Li - Xin-Min Shen \\ PLA Army Engineering University, College of Field Engineering, China
}

Energy management strategy is a critical technology for improving the fuel economy of wheel-drive hydraulic hybrid vehicles. For driving, a power-following control strategy is proposed in this study by adding several working points of the engine in the optimal fuel economy power curve. For braking, the "I" curve distribution strategy based on critical braking strength $z_{\min }$ was adopted. A test bench was constructed according to the quarter of the prototype vehicle. Taking the typical working conditions of Federal Urban Driving Schedule (FUDS) and the selfset extra-urban driving schedule (EUDC-1) cycle condition into consideration, the energy management strategy was studied. The torque and speed of the simulated engine and pressure of the accumulator were obtained. The test fuel consumption in this research was compared with the original fuel consumption of the prototype vehicle. It was found that the proposed energy management strategy could effectively improve the fuel economy by more than $24 \%$ under the requirement of satisfying the dynamic performance of the whole vehicle.

Keywords: wheel-drive hydraulic hybrid vehicle, power-following control strategy, braking force distribution strategy, drive cycle, fuel economy

\section{Highlights}

- A power-following control strategy was proposed by adding several working points of the engine in the optimal fuel economy power curve.

- The "I" curve distribution strategy based on the critical braking strength zmin was adopted.

- The energy management strategy in this study satisfied the dynamic performance of the whole vehicle.

- $\quad$ Results showed that the proposed energy management strategy could improve the fuel economy by more than $24 \%$ in the test bench.

\section{INTRODUCTION}

The secondary regulation technology for the constant pressure network was introduced and applied to a hybrid tactical vehicle including the series connections of an internal combustion engine (ICE), hydraulic pump, and the novel hydraulic pump/motor. The wheel-drive technology was used to improve the ground clearance of vehicle chassis [1], and the fuel economy of the vehicle could be improved by using the appropriate energy management strategy.

Currently, most of the energy management strategies of the hydraulic hybrid vehicles come from related research about hybrid electric vehicles [2] to [8]. Because of being controlled simply and applied conveniently, the rule-based energy management strategy is the most widely used one among them. The main idea of the strategy is to judge the working area of the ICE and switch the working modes of the vehicle, in order to make the ICE run in an efficient manner corresponding to controller variables (including the power demand, speed of the vehicle, and the accumulator state of charge (SOC), etc.) [2]. For a wheel-drive hydraulic hybrid vehicle (WDHHV), because of the small energy density and high power density of the accumulator, the engine usually worked in the frequent start-stop state, which hindered the improvement of the fuel economy of the vehicle [3]. For the control strategy of the accumulator $S O C$, according to the characteristics of the low power density of the accumulator, the main parameter accumulator $S O C_{\max }$ and $S O C_{\min }$ of this strategy were optimized, and it was found that when the parameters were 0.7 and 0.1 , respectively, the fuel economy could be increased by more than $30 \%$, although the dynamic performance of the system was not so good [4]. For the control strategy of the engine state, the power-following control strategy was proposed by Song et al. for a series of electric drive bulldozers based on typical operating conditions [5]. The results indicated that not only was the dynamic performance of the bulldozer satisfied, but the fuel economy also was increased by $13.1 \%$.

\section{METHODS}

In this study, according to their characters, two control strategies were selected for WDHHV. For driving, a power-following control strategy was proposed for adding several engine working points in the optimal fuel economy power curve of the ICE. For braking, considering the minimum braking force that could be 
provided through the variable displacement motor/ pump and SOC of the accumulator [6], the "I" curve distribution strategy based on critical braking strength $z_{\min }$ was adopted to fully recover the braking energy. At present, most of the research on the energy management strategy of the WDHHV has remained in the simulation stage [3], [7] to [9], which is not sufficiently credible for practical application. To conduct the study, a test bench was built, on which an electric motor was used to simulate the ICE. Meanwhile, the motor energy consumption was converted into the ICE fuel consumption, measuring on one-hundred-kilometres and was compared with that of the prototype vehicle.

\section{CONFIGURATION}

Configuration of the WDHHV was shown in Fig. 1. It included ICE (diesel engine), constant pressure variable pump, high-voltage accumulator, low-voltage accumulator (replace tank), direction control valves, hydraulic variable displacement motor/pump, wheels, vehicle controller, and so on.

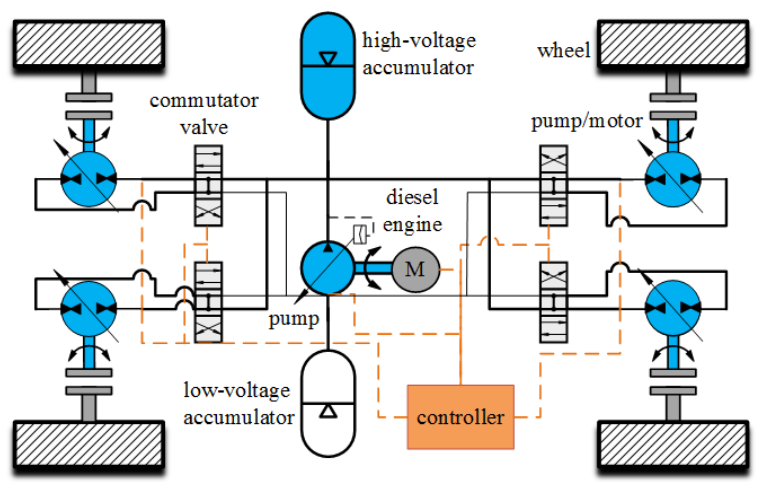

Fig. 1. Configuration of the WDHHV

The ICE directly drives the pump, which adjusts the displacement to maintain the constant pressure of the system [10]. Therefore, the ICE working condition is independent of the external load to work in the area with high fuel economy [11]. Each wheel is driven independently by a hydraulic motor/pump, which can work in four quadrants. In the driving phase, the accumulator acts as the auxiliary power source. The hydraulic motor/pump is working in the "motor" state and converts the hydraulic energy into the mechanical energy, and the vehicle can achieve infinite speed regulation by adjusting the displacement of the hydraulic motor/pump. In the braking phase, the hydraulic motor/pump works in the "pump" state and converts the kinetic energy of the vehicle into the hydraulic energy stored in the accumulator, which can be released and reused in the driving phase [12].

\section{CONTROL SYRATEGIES}

\subsection{Drive Strategy}

According to the configuration of WDHHV in Fig. 1 , there are two power sources (the engine and the accumulator) and two braking methods (regenerative braking and friction braking). We can make six working modes of the vehicle, which are shown in Table 1 [13].

Table 1. Working modes of the vehicle

\begin{tabular}{cc}
\hline & Working modes \\
\hline 1 & Accumulator drive mode \\
\hline 2 & Engine drive mode \\
\hline 3 & Accumulator+ Engine drive mode \\
\hline 4 & Friction braking \\
\hline 5 & Regenerative braking \\
\hline 6 & Friction+ Regenerative braking \\
\hline
\end{tabular}

The engine model adopts the experimental modelling, and brake-specific fuel consumption (BSFC) is obtained by the interpolation based on the actual engine experimental data provided by the manufacturer. Fuel consumption of the engine can be obtained according to Eq. (1) [14].

$$
B=\int g_{e} P_{e} d t=\int T_{e} n_{e} f\left(T_{e}, n_{e}\right) d t,
$$

where $B$ is the fuel consumption $[\mathrm{g}], P_{e}$ is the engine power $[\mathrm{kW}]$, and $g_{e}$ is fuel consumption rate $[\mathrm{g} /(\mathrm{kW} \cdot \mathrm{h})]$.

According to the real-time state of the vehicle (power demand, vehicle speed, accumulator SOC) and energy allocation strategy, the target required power of the engine can be obtained at each sampling time. Since there is an energy coupling relationship between the engine and load, there is no longer a direct mechanical relationship between the engine speed and the vehicle speed. Therefore, the engine can work in the optimal fuel consumption curves preset according to the power demand and the universal characteristic of engine [15]. The strategy could effectively avoid the frequent ICE dynamic switching, so that the ICE works on the minimum fuel consumption curve and switches to a reasonable mode of the operation. The engine regulation rules are shown in Fig. 2.

In Fig. $2 P_{r e q}$ and $P_{\max }$ are the power required and the maximum power of the engine, respectively. $P_{B S F C}$ are the candidate operating points in Fig. 3. 


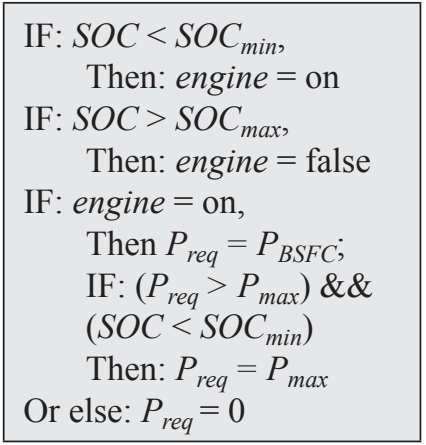

Fig. 2. Engine regulation rules

At the same time, many studies [16] to [19] on the hybrid vehicles showed that the engine works in the start-stop mode, which was beneficial to fuel economy. Therefore, the engine start-stop mode was selected. The optimal fuel economy curve of the engine was shown in Fig. 3.

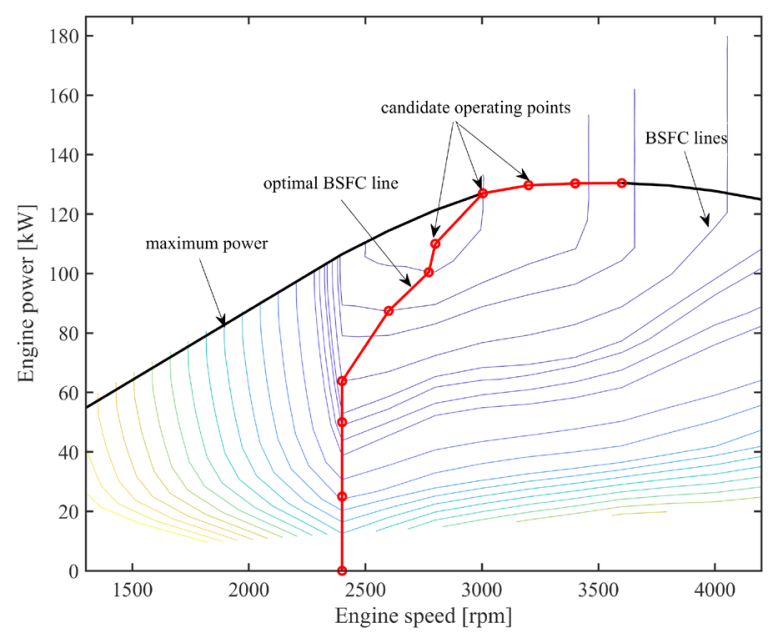

Fig. 3. Optimal fuel economy curve of the engine

\subsection{Braking Strategy}

There are two kinds of braking modes in the WDHHV: regenerative braking and friction braking [20]. Regenerative braking is to make hydraulic motor/ pump work in the "pump" state to achieve energy recovery and braking. Friction braking sheets are used to brake the vehicle in the form of heat dissipation. The braking strategy is to reasonably configure the two braking modes to fully recover the braking energy under the premise of satisfying the braking performance requirement of the vehicle [21].

In this study, an "I" curve control strategy based on the critical braking strength $z_{\min }$ was adopted [22].
The top-level block diagram of the braking control strategy is shown in Fig. 4.

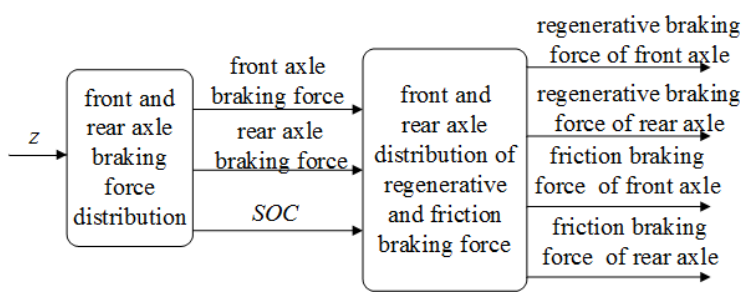

Fig. 4. Schematic diagram of braking control strategy

The ideal relationship curve of the front and rear wheel braking force was called the "I" curve, that is, the ideal braking power distribution curve, as shown in the Fig. 5. At this time, the braking stability and adhesion conditions were better utilized [23], and the front and rear axle braking force are shown in Eqs. (2) and (3) respectively.

$$
\begin{gathered}
G \varphi=F_{\mu 1}+F_{\mu 2}, \\
\frac{F_{\mu 1}}{F_{\mu 2}}=\frac{b+\varphi h_{g}}{a-\varphi h_{g}}, \\
F_{\mu 2}=\frac{1}{2}\left[\frac{G}{h_{g}} \sqrt{b^{2}+\frac{4 h_{g} L}{G} F_{\mu 1}}-\left(\frac{G b}{h_{g}}+2 F_{\mu 1}\right)\right],
\end{gathered}
$$

where $F_{\mu 1}$ and $F_{\mu 2}$ are the front and rear axle braking force respectively [N]; $G$ is gravity of the vehicle [N]; $h_{g}$ is the height of mass centre [m]; $a$ and $b$ are the distance from mass centre to rear axle and to front rear, respectively $[\mathrm{m}] ; L$ is the distance between the shafts $[\mathrm{m}]$ and $\varphi$ is the adhesion coefficient on road surface [-].

The actual braking forces of the front and rear axle were generally composed of the friction braking force and regenerative braking force. To maximize the recovery of braking energy, the variable motor/ pump braking mode should be considered first. If requirements of the front (or rear) shaft were less than the motor braking force, the variable displacement motor/pump acted as a pump while mechanical braking did not work, as shown in point in Fig. 5. If the demand braking force of the front (or the rear) shaft was larger than that of the braking force of the motor/pump, the latter produced the maximum braking force, and the remaining part of the braking force was supplemented by friction braking, as shown of point $\mathrm{c}$ in the Fig. 5 .

$$
F_{m}=\frac{T_{w}}{r},
$$




$$
T_{w}=\frac{\Delta P V}{2 \pi},
$$

where $F_{m}$ is the brake force of wheels [N]; $T_{w}$ is the brake torque of wheels, $[\mathrm{N} \cdot \mathrm{m}] ; \Delta P$ is the pressure drop of the variable displacement motor/pump $[\mathrm{Pa}] ; V$ is the displacement of the motor/pump $\left[\mathrm{m}^{3} / \mathrm{r}\right]$, and $r$ is the radius of wheels [m].

Then the minimum regenerative braking power of the front axle is shown in Eq. (7):

$$
F_{\mu 1}=\frac{\Delta P V}{\pi r} .
$$

With this method, Eqs. (8) and (9) could be obtained.

$$
\begin{aligned}
& \frac{F_{\mu 1}}{G}=0.18, \\
& \frac{F_{\mu 2}}{G}=0.17 .
\end{aligned}
$$

Thus, the critical braking strength is $z_{\min }=0.35$, as is shown in point $b$ in Fig. 5.

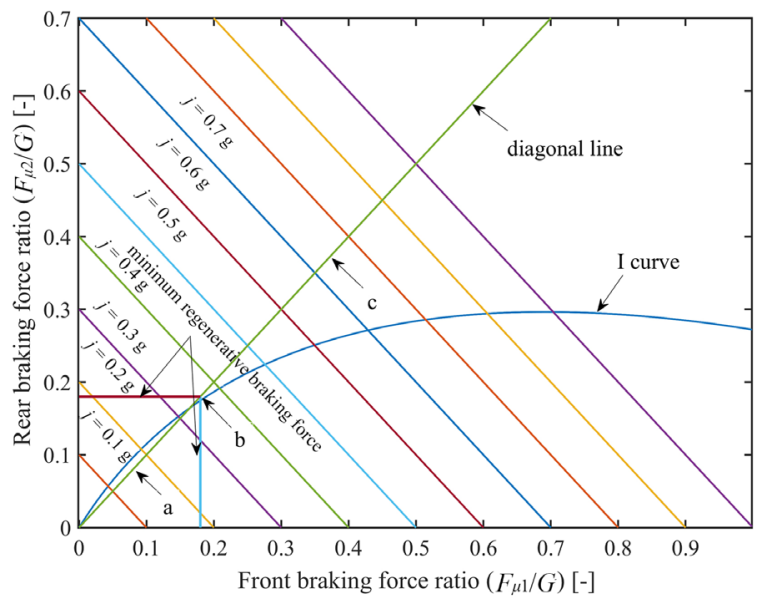

Fig. 5. Ideal front and rear axle braking force distribution curve

Combined with critical braking strength $z_{\min }$, the braking strategy based on the "I" curve is distributed as follows.

(1) $z<0.35$, regenerative braking. Friction braking did not participate in the work, and the front and rear braking forces were distributed according to the "I" curve.

$$
\begin{gathered}
\left\{\begin{array}{l}
G z=F_{\mu 1}+F_{\mu 2} \\
\frac{F_{\mu 1}}{F_{\mu 2}}=\frac{b+\varphi h_{g}}{a-\varphi h_{g}},
\end{array}\right. \\
\left\{\begin{array}{l}
F_{\mu 1 m}=0 \\
F_{\mu 2 m}=0
\end{array}\right.
\end{gathered}
$$

where $F_{\mu 1 m}$ and $F_{\mu 2 m}$ are the front and rear axle friction braking force, respectively $[\mathrm{N}]$.

(2) $0.35<z<0.7$, mixed braking. Firstly, considering regenerative braking, the insufficient part was supplied by friction braking.

$$
\begin{gathered}
\left\{\begin{array}{l}
G z=F_{\mu 1}+F_{\mu 2} \\
\frac{F_{\mu 1}}{F_{\mu 2}}=\frac{b+\varphi h_{g}}{a-\varphi h_{g}},
\end{array}\right. \\
\left\{\begin{array}{l}
F_{\mu 1 m}=F_{\mu 1}-F_{\mu 1 p / m} \\
F_{\mu 2 m}=F_{\mu 2}-F_{\mu 2 p / m}
\end{array},\right.
\end{gathered}
$$

where $F_{\mu 1 m / p}$ and $F_{\mu 2 m / p}$ are the front and rear axle regenerative braking force, respectively $[\mathrm{N}]$.

(3) $z>0.7$, friction braking. Take the maximum friction braking force with the ground adhesion coefficient 0.7 , and the front and rear braking force were distributed according to the "I" curve.

$$
\begin{gathered}
\left\{\begin{array}{c}
G \times 0.7=F_{\mu 1}+F_{\mu 2} \\
\frac{F_{\mu 1}}{F_{\mu 2}}=\frac{b+\varphi h_{g}}{a-\varphi h_{g}}
\end{array},\right. \\
\left\{\begin{array}{l}
F_{\mu 1 p / m}=0 \\
F_{\mu 2 p / m}=0
\end{array}\right.
\end{gathered}
$$

The maximum braking force of the front axle was $8748 \mathrm{~N}$, and the maximum braking force of the rear axle was $5760 \mathrm{~N}$.

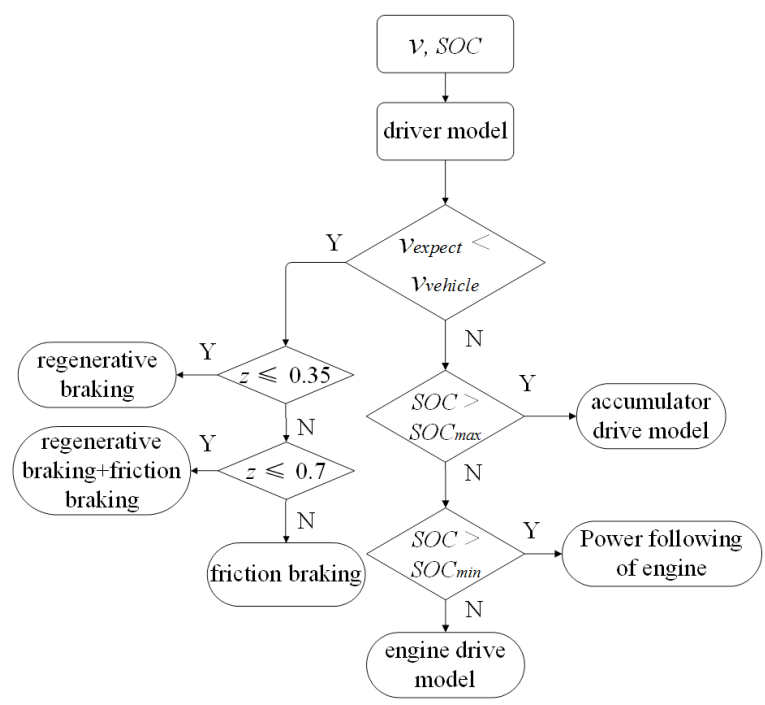

Fig. 6. Energy management control strategy

The ICE adjustment strategy and working modes switching rules were shown in Fig. 6. In the flowchart, $z$ was the braking strength. 


$$
z=\frac{a_{1}}{g}
$$

where $a_{1}$ is the brake deceleration $\left[\mathrm{m} / \mathrm{s}^{2}\right] ; g$ is the gravity acceleration $\left[\mathrm{m} / \mathrm{s}^{2}\right]$. The upper and lower limits of the accumulator $S O C_{\max }$ and $S O C_{\min }$ are 0.6 and 0.2 , respectively [4].

$$
S O C=\frac{P_{c}-P_{\min }}{P_{\max }-P_{\min }},
$$

where $P_{c}$ is the current pressure of the air cavity of the accumulator [bar]; $P_{\max }$ and $P_{\min }$ are the maximum and minimum allowable working pressures of the accumulator respectively [bar].

\section{EXPERIMENTAL}

The adopted test method was the cyclic fuel consumption method, which referred to the fuel consumption of the vehicle at a certain speed, as well as acceleration and deceleration on a specified typical road section. The test bench used the motor instead of the ICE as the power source. Therefore, the electric power consumption of the motor must be converted into ICE fuel consumption on a one-hundredkilometre route and then compared with the prototype vehicle.

\subsection{Test Bench}

The test bench was based on one quarter of the prototype vehicle, and the hydraulic system was shown in Fig. 7.

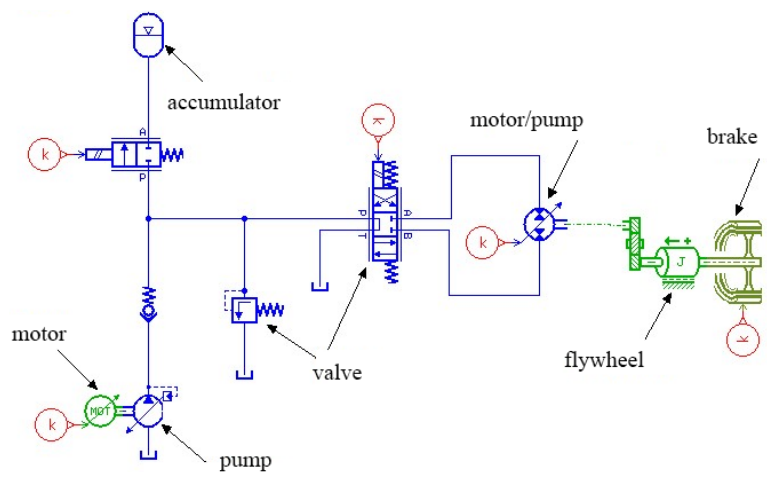

Fig. 7. Hydraulic system block diagram of test bench

The test bench is shown in Fig. 8. It was composed of an electric motor (instead of an ICE), a constant pressure variable pump, accumulators, a variable displacement hydraulic motor/pump, magnetic powder brake (to simulate the friction braking), flywheels (the inertia moment of the flywheel simulates inertia moment of a quarter of the vehicle), and the control system. The selected parameters for the test bench were shown in Table 2.

a)

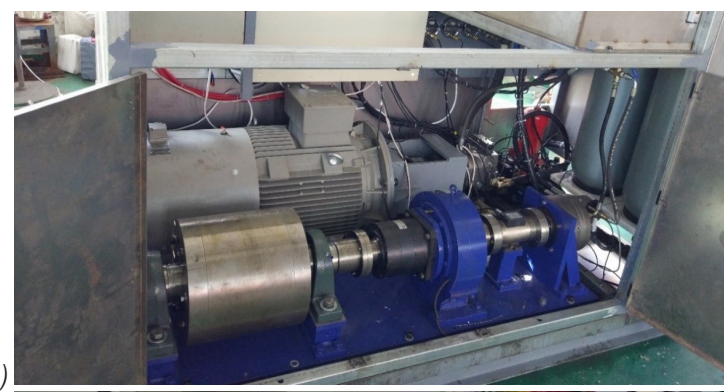

b)

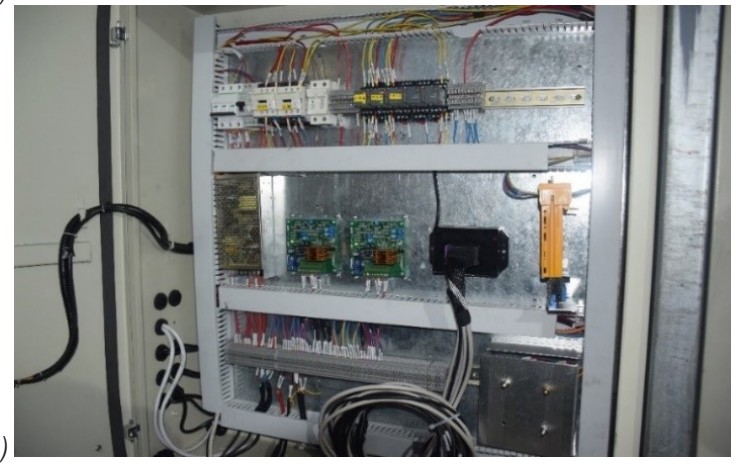

Fig. 8. Test bench; a) internal connection of test bench; and b) control panel of test bench

Table 2. Parameter configuration of test bench

\begin{tabular}{lc}
\hline Parameters & value \\
\hline Motor rated power, [kW] & 75.0 \\
\hline Variable pump displacement, [mL/r] & 46.0 \\
\hline Inertial flywheel moment of inertia, [kg·m²] & 6.578 \\
\hline Overflow valve setting pressure, [bar] & 250.0 \\
\hline Accumulator pre-charge pressure, [bar] & 160.0 \\
\hline Gear ratio [-] & $1: 4$ \\
\hline Variable motor/pump displacement, [mL/r] & 180.0 \\
\hline Accumulator volume, [L] & 63.0 \\
\hline
\end{tabular}

\subsection{Breaking Test}

The brake strength was $z=0.35$, which was the critical braking strength. The system pressure was 180 bar. The test process: accelerate flywheel to 200 $\mathrm{rpm}$ (equal to vehicle speed at $18 \mathrm{~m} / \mathrm{s}$ ) and maintain its speed; set the hydraulic motor/pump displacement to $180 \mathrm{~mL} / \mathrm{r}$, and keep working in the hydraulic pump state; brake flywheel until the speed was $0 \mathrm{rpm}$, while energy was transformed into hydraulic energy to charge the accumulator. The obtained test curve is shown in Fig. 9.

The brake strength was $z=0.5$, which was in mixed braking mode. The system pressure was 180 
bar. Test process: accelerate the flywheel to $200 \mathrm{rpm}$ and maintain the speed stability; set the hydraulic motor/pump displacement to $180 \mathrm{~mL} / \mathrm{r}$ and work in the hydraulic pump state; According to brake pedal signal, the central controller calculates the friction braking torque $235 \mathrm{~N} \cdot \mathrm{m}$; brake flywheel until the speed was $0 \mathrm{rpm}$, while the energy was converted into the hydraulic energy to charge the accumulator. The test curve is shown in Fig. 10.

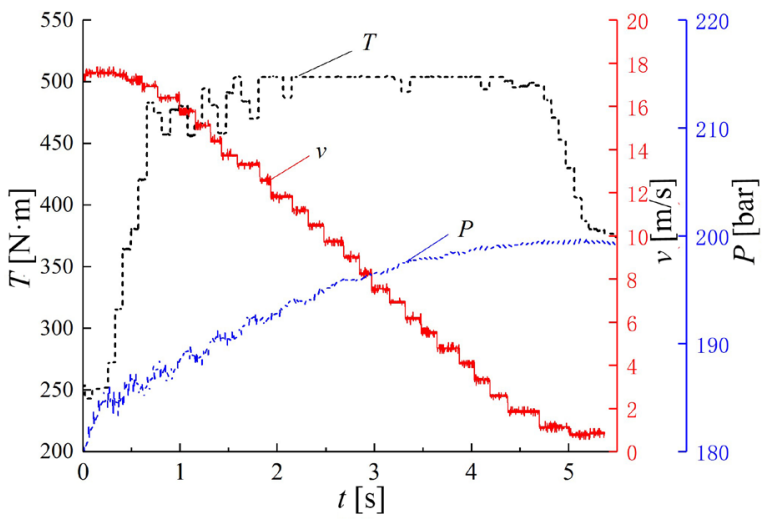

Fig. 9. Profile of regenerative braking torque, vehicle speed and accumulator pressure

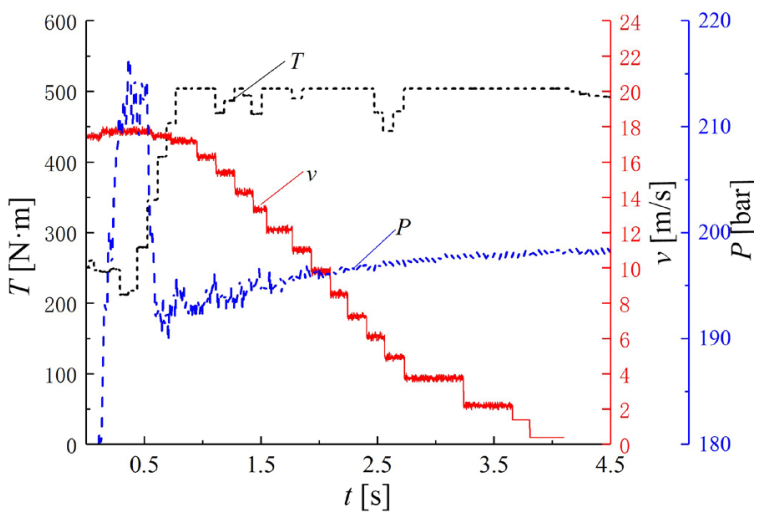

Fig. 10. Profile of regenerative braking torque, vehicle speed and accumulator pressure

The test results indicated that the bench could meet the requirement of test and verify the correctness of the control strategy as well.

\subsection{Cycle Conditions Test}

\subsubsection{Drive Cycle}

The test was carried out in two cycle conditions (the FUDS cycle and the EUDC-1 cycle), considering the actual operating characteristics of the WDHHV. According to the national standard (GB 14671.1-
93) "vehicle test operating conditions" and technical specifications of tactical vehicles, the EUDC- 1 cycle was designed from $0 \mathrm{~km} / \mathrm{h}$ to $130 \mathrm{~km} / \mathrm{h}$, including multiple accelerations deceleration stages to simulate the driving characters of the tactical vehicles on the off-road. The speed profile of driving conditions are shown in Figs. 11 and 12, respectively.

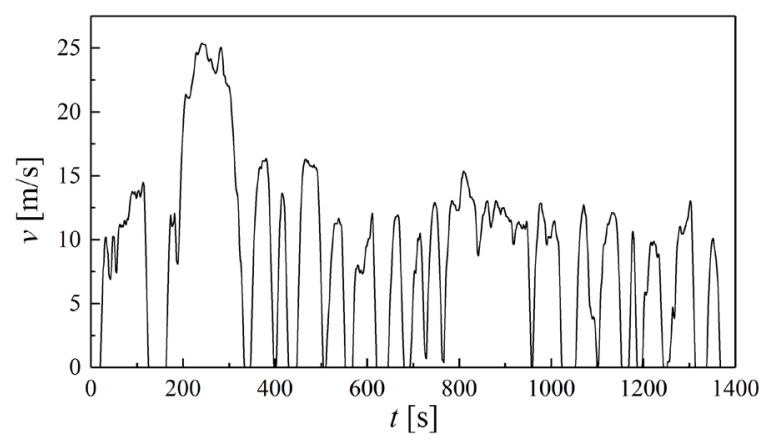

Fig. 11. FUDS cycle condition

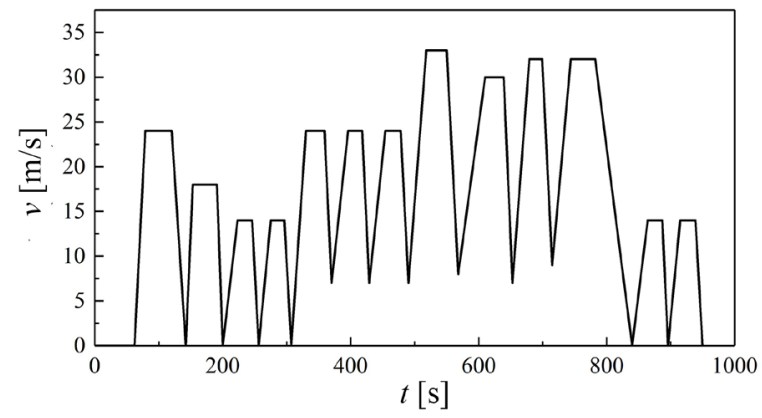

Fig. 12. EUDC-1 cycle condition

\subsubsection{Calculation of Fuel Economy}

The test bench in this study uses a motor instead of an engine. From the perspective of providing energy, using a motor instead of an engine, we obtained the electrical energy consumption of the motor and converted it into corresponding fuel consumption, in which fuel economy can be compared [24]. The simulation procedure of ICE by using an electric motor is shown in Fig. 13.

The motor energy consumption represents the ICE consumption of the whole system. The torque and speed of the motor could be measured by the test bench, which could be used to calculate the motor power, as shown in the Eq. (18).

$$
P_{m}=\frac{T_{m} \cdot n_{m}}{9550}
$$

where $P_{m}$ is the motor power $[\mathrm{kW}], T_{m}$ the motor torque $[\mathrm{N} \cdot \mathrm{m}]$ and $n_{m}$ the motor speed [rpm]. 


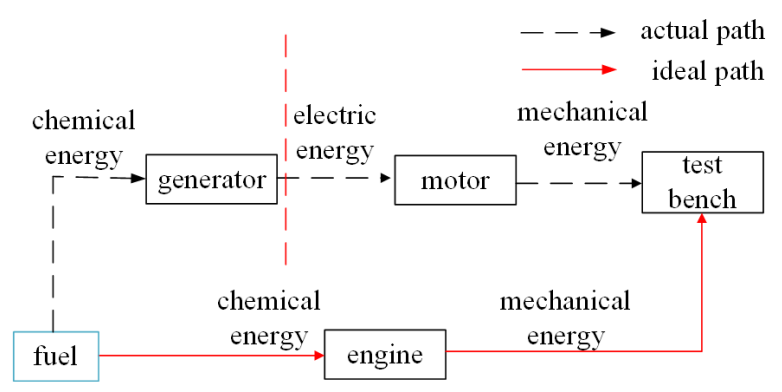

Fig. 13. The simulation procedure of ICE by using an electric motor

The power curve of the motor was obtained, and the energy consumption $W$ under the cycle condition could be obtained by the time integral of the power curve. The total fuel consumption could be obtained by origin software in the study. Similarly, making integral for the speed curve can obtain the mileage $S$ of the cycle condition. Therefore, the power consumption of one hundred kilometres $M$ was shown in Eq. (19).

$$
M=\frac{W}{S} \times 100 .
$$

Since the test bench simulated the load of a quarter of vehicle, the power consumption on one-hundredkilometre $M$ was converted to fuel consumption.

$$
F=\frac{M}{m_{\text {oil }} \mathrm{b}_{\text {oil }} \eta} \times \mathrm{k}
$$

where $F$ is the fuel consumption per hundred kilometres. $m_{\mathrm{oil}}$ is the mass of $1 \mathrm{~L}$ diesel oil. $\mathrm{b}_{\mathrm{oil}}$ is the calorific value of $4.6 \times 10^{7} \mathrm{~J} / \mathrm{kg}$. $\eta$ is the fuel efficiency of 0.31 , and $\mathrm{k}$ is 4.0 .

\subsubsection{Test Results}

Under FUDS cycle conditions, the profiles of vehicle speed, electric motor speed, motor torque, motor power and system pressure are shown in Fig. 14.

Fig. 14a represented the speed profile. Compared with Fig. 11, it was clear that there was some error between the speed profiles, but it would not affect the experimental results. Fig. 14b represented the electric motor speed profile. It could be seen that there were three different stages of motor speeds, which was corresponding to three different motor working points and effectively reducing the motor's frequent startstop in the $0 \mathrm{~s}$ to $400 \mathrm{~s}$ to reduce energy consumption. Fig. $14 \mathrm{~d}$ was the motor power profile, and the energy consumption was $1433.28 \mathrm{~kJ}$. Integrating Fig. 14a could attain the entire cycle mileage $6.1 \mathrm{~km}$. Fig. $14 \mathrm{e}$ represented the pressure profile of the hybrid system.

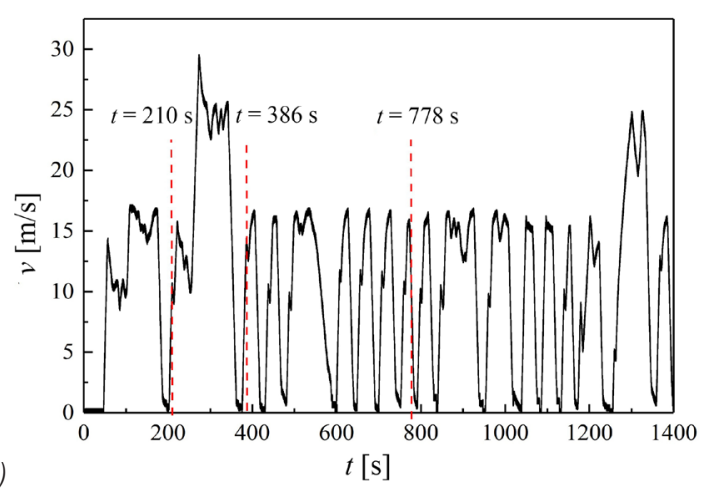

a)

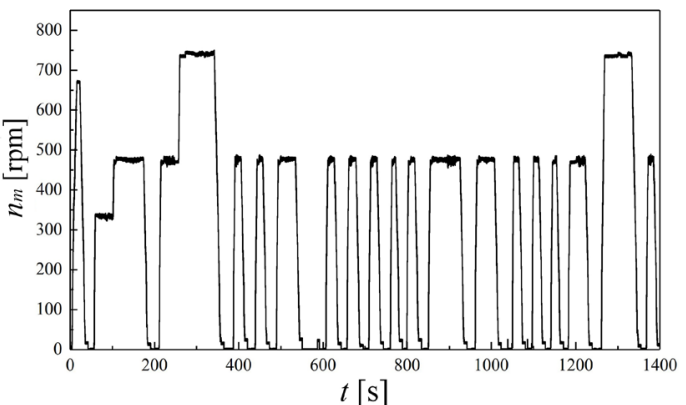

b)
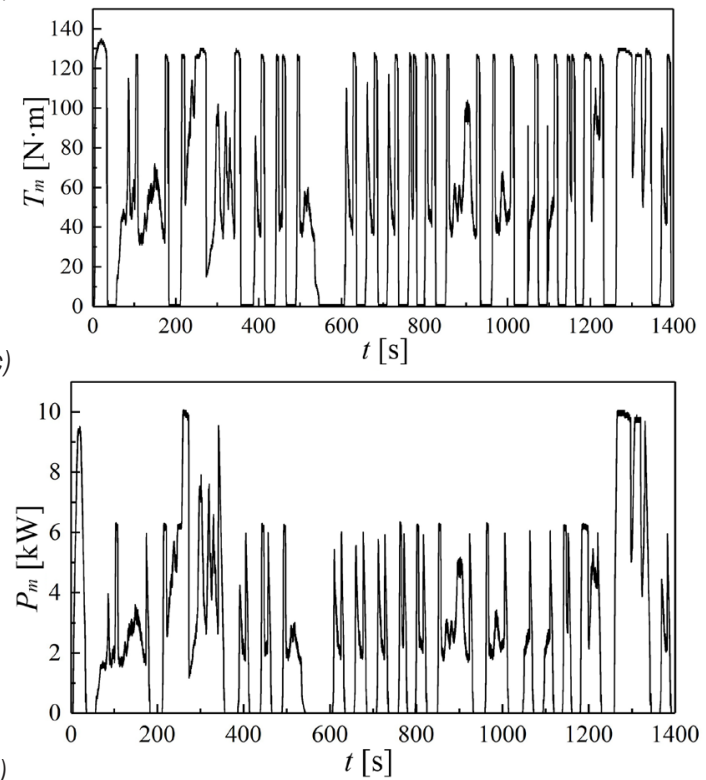

d)

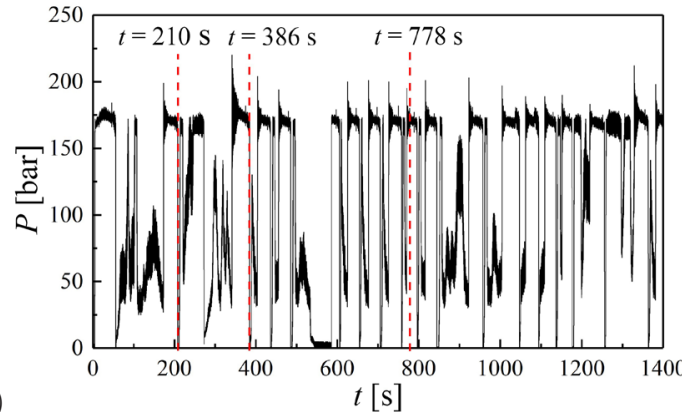

Fig. 14. Variation of parameters under FUDS cycle; a) vehicle speed profile, b) electric motor speed profile, c) motor torque profile, d) motor power profile, and e) loop pressure profile 

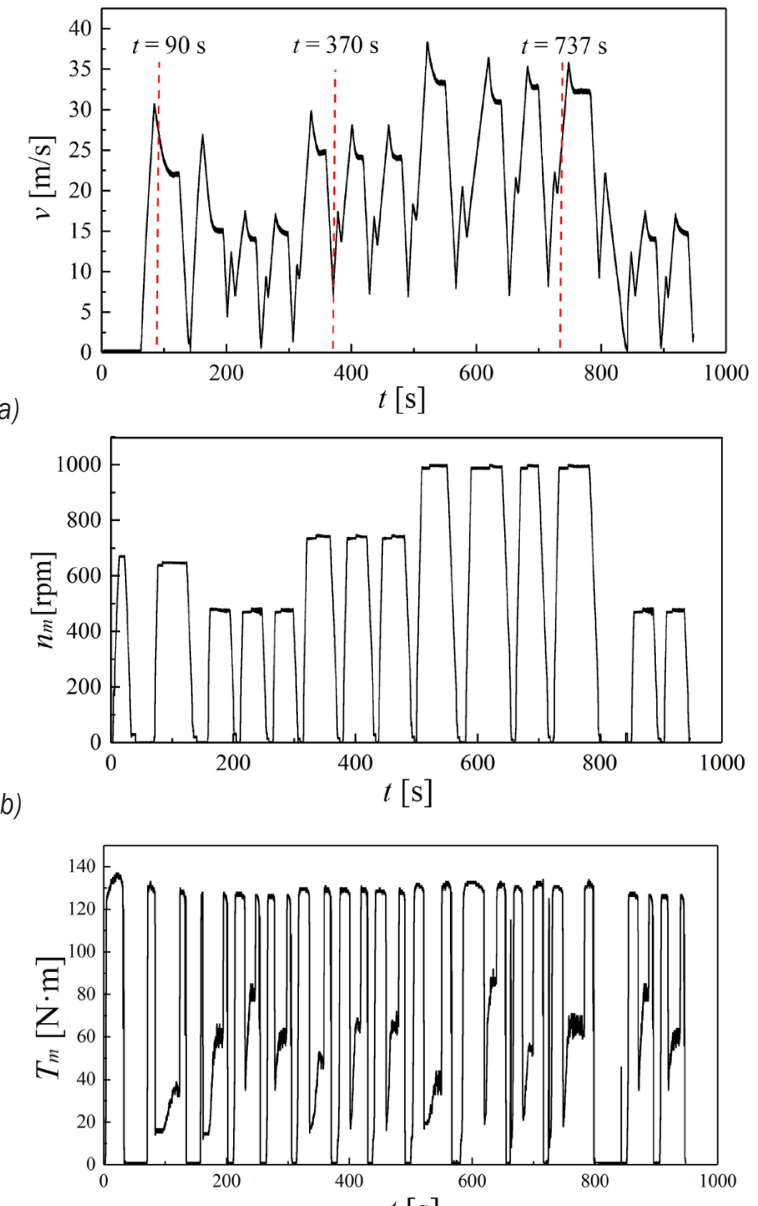

C)

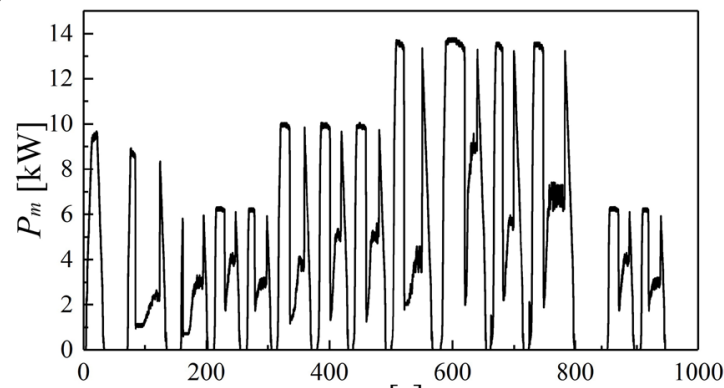

d)

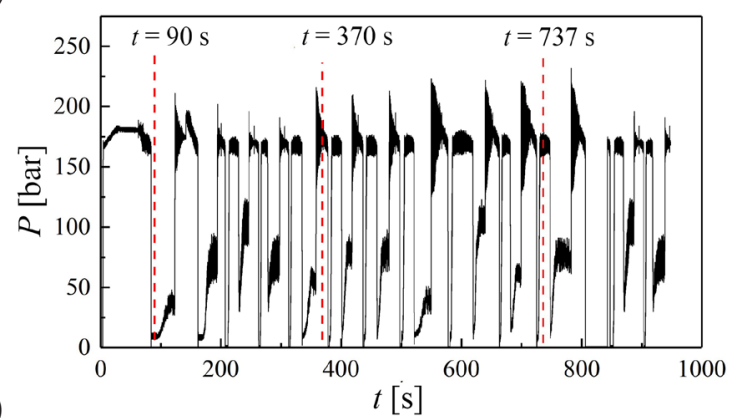

Fig. 15. Variation of parameters under EUDC-1 cycle; a) vehicle speed profile, b) electric motor speed profile, c) motor torque profile, d) motor power profile, and e) loop pressure profile
Compared with Fig. 14a, it could be seen that at 210 s, $386 \mathrm{~s}, 778 \mathrm{~s}$, and other time points, the system pressures and speed change time were basically the same, indicating that the accumulator could realize the recovery and reuse of the vehicle braking energy.

Under the EUDC-1 cycle condition, the change of the vehicle speed, electric motor speed, motor torque, motor power and system pressure are shown in Fig. 15.

Fig. 15a was the vehicle speed profile. Compared with Fig. 12, the speed profile was basically consistent with that of the cycle condition curve. Fig. 15b was the electric motor speed profile. It was obvious that there were four different stages of motor speed, which represented four different motor working points and be greatly reducing the motor frequent start-stop and energy consumption. For Fig. 15d and Fig. 15a, the energy consumed by the integral of the whole cycle was $2003.84 \mathrm{~kJ}$, and the mileage was $8.3 \mathrm{~km}$, respectively. Fig. $15 \mathrm{e}$ was the pressure profile of the hybrid system. Compared with Fig. 15a, it could be seen that at $90 \mathrm{~s}, 370 \mathrm{~s}, 737 \mathrm{~s}$, and other time points, the system pressures and speed change time were basically the same, and the accumulator could realize the recovery and reuse of vehicle braking energy.

The above test results were brought into Eqs. (18) and (19), respectively, and the improvement of fuel economy us shown in Table 3.

Table 3. Improvement of fuel economy

\begin{tabular}{|c|c|c|c|}
\hline $\begin{array}{l}\text { Working } \\
\text { condition }\end{array}$ & $\begin{array}{c}\text { test, } \\
\mathrm{L} / 100 \mathrm{~km}\end{array}$ & $\begin{array}{l}\text { prototype, } \\
\text { L/100 km }\end{array}$ & $\begin{array}{c}\text { Improvement } \\
{[\%]}\end{array}$ \\
\hline FUDS & 7.80 & \multirow{2}{*}{11} & 29.09 \\
\hline EUDC-1 & 8.32 & & 24.36 \\
\hline
\end{tabular}

\section{CONCLUSIONS}

1) The working principle of the WDHHV was analysed. For driving, a power-following control strategy was designed based on the optimal fuel economy power curve. On the braking hand, the "I" curve distribution strategy based on the critical braking strength $z_{\min }$ was adopted. The control strategy was tested under the cycle condition of FUDS and EUDC-1, and finally be compared with fuel consumption of the prototype vehicle.

2) The test results showed that under the two cycle conditions the energy management strategy proposed in this research could meet the vehicle dynamic performance requirements, and the fuel 
economy could be increased by more than 24 $\%$ compared with the prototype vehicle, which verified the effectiveness of the proposed energy management strategy.

3) On the test bench, the fuel economy of the FUDS cycle condition could be increased by $4.73 \%$ compared with the EUDC-1 cycle, which was due to the frequent start-stop stages of FUDS cycle. Thus, the energy could be fully recovered and reused, and fuel consumption of the engine was effectively reduced.

4) The test bench built in this study had certain errors due to using the motor to simulate the ICE, so further research of the control strategy will be conducted on real vehicles.

\section{ACKNOWLEDGEMENTS}

This work was supported and funded by a grant from National Natural Science Foundation of China (Grant No. 51505498), a grant from Natural Science Foundation of Jiangsu Province (Grant No. BK20150714), and a grant from National Key R \& D Program of China (Grant No. 2016YFC0802900).

\section{NOMENCLATURES}

\begin{tabular}{|c|c|}
\hline$B$ & fuel consumption, [g] \\
\hline$P_{e}$ & engine power, $[\mathrm{kW}]$ \\
\hline$g_{e}$ & fuel consumption rate, $[\mathrm{g} /(\mathrm{kW} \cdot \mathrm{h})]$ \\
\hline$T_{e}$ & engine torque, $[\mathrm{N} \cdot \mathrm{m}]$ \\
\hline$n_{e}$ & engine speed, [rpm] \\
\hline$t$ & time, $[\mathrm{s}]$ \\
\hline$P_{\text {req }}$ & power required of engine, $[\mathrm{kW}]$ \\
\hline$P_{\max }$ & maximum power of engine, $[\mathrm{kW}]$ \\
\hline$P_{B S F C}$ & candidate operating points of the ICE, $[\mathrm{kW}]$ \\
\hline$F_{\mu 1}$ & front axle braking force, $[\mathrm{N}]$ \\
\hline$F_{\mu 2}$ & rear axle braking force, $[\mathrm{N}]$ \\
\hline$G$ & gravity of vehicle, $[\mathrm{N}]$ \\
\hline$h_{g}$ & height of mass centre, $[\mathrm{m}]$ \\
\hline$a, b$ & $\begin{array}{l}\text { distance from mass centre to rear axle and } \\
\text { front rear respectively, }[\mathrm{m}]\end{array}$ \\
\hline$L$ & distance between shafts, $[\mathrm{m}]$ \\
\hline$\varphi$ & adhesion coefficient on road surface \\
\hline$F_{m}$ & brake force of wheels, $[\mathrm{N}]$ \\
\hline$T_{w}$ & brake torque of wheels, $[\mathrm{N} \cdot \mathrm{m}]$ \\
\hline$\Delta P$ & $\begin{array}{l}\text { pressure drop of variable displacement } \\
\text { motor/pump, }[\mathrm{Pa}]\end{array}$ \\
\hline$V$ & displacement of motor/pump, $\left[\mathrm{m}^{3 / \mathrm{r}}\right]$ \\
\hline$r$ & radius of wheels, $[\mathrm{m}]$ \\
\hline$z$ & braking strength, $[-]$ \\
\hline & critical braking strength, $[-]$ \\
\hline
\end{tabular}

$S O C_{\min }$ lower limit of the accumulator $S O C$, [-]

$F_{\mu 1 \mathrm{~m}} \quad$ front axle friction braking force, [N]

$F_{\mu 2 m} \quad$ rear axle friction braking force, [N]

$F_{\mu 1 p / m}$ front axle regenerative braking force, [N]

$F_{\mu 2 p / m} \quad$ rear axle regenerative braking force, [N]

$a_{1} \quad$ brake deceleration, $\left[\mathrm{m} / \mathrm{s}^{2}\right]$

$g \quad$ gravity acceleration, $\left[\mathrm{m} / \mathrm{s}^{2}\right]$

$P_{c} \quad$ current pressure of the air cavity of the accumulator, [bar]

$P_{\max } \quad$ maximum allowable working pressures of the accumulator respectively, [bar]

$P_{\min } \quad$ minimum allowable working pressures of the accumulator respectively, [bar]

$T_{m} \quad$ the motor torque, $[\mathrm{N} \cdot \mathrm{m}]$

$P_{m} \quad$ the motor power, $[\mathrm{kW}]$

$n_{m} \quad$ the motor speed, [rpm]

$P \quad$ the accumulator pressure, [bar]

$F \quad$ fuel consumption of one hundred kilometres, [L]

$W \quad$ energy consumption under the cycle condition, $[\mathrm{kJ}]$

$M \quad$ power consumption on one-hundredkilometre route, $[\mathrm{kJ}]$

$S \quad$ mileage of the cycle condition, [km]

$m_{\text {oil }} \quad$ mass of $1 \mathrm{~L}$ diesel oil, [kg]

$\mathrm{b}_{\mathrm{oil}} \quad$ calorific value, $4.6 \times 10^{7} \mathrm{~J} / \mathrm{kg}$

$\eta \quad$ fuel efficiency, 0.31

$\mathrm{k} \quad$ conversion factor between bench and whole vehicle, 4.0

\section{REFERENCES}

[1] Shabbir, W., Evangelou, S.A. (2019). Threshold-changing control strategy for series hybrid electric vehicles. Applied Energy, vol. 235, p. 761-775, D01:10.1016/j. apenergy.2018.11.003.

[2] Chen, J.-S. (2015). Energy efficiency comparison between hydraulic hybrid and hybrid electric vehicles. Energies, vol. 8, no. 6, p. 4697-4723, Dol:10.3390/en8064697.

[3] Feng, D., Huang, D., Li, D. (2011). Stochastic model predictive energy management for series hydraulic hybrid vehicle. IEEE International Conference on Mechatronics \& Automation, p. 1980-1986, DOI:10.1109/ICMA.2011.5986284.

[4] Pfeffer, A., Glück, T., Kemmetmüller, W., Kugi, A. (2016). Mathematical modelling of a hydraulic accumulator for hydraulic hybrid drives. Mathematical and Computer Modelling of Dynamical Systems, vol. 22, no. 5, p. 397-411, D0l:10.1080 /13873954.2016.1174716.

[5] Song, Q., Zeng, P., He, S., Wang, H. (2014). Power follow control strategy of series electric drive bulldozer based on typical operating conditions. Journal of Mechanical Engineering, vol. 50, no. 20, p. 136-142, Dol:10.39001/JME.2014.20.136.

[6] Hui, S. (2010). Multi-objective optimization for hydraulic hybrid vehicle based on adaptive simulated annealing genetic algorithm. Engineering Applications of Artificial 
Intelligence, vol. 23, no. 1, p. 27-33, Dol:10.1016/jengappai.7. 2009.09.005.

[7] Bravo, R.R.S., De Negri, V.J., Oliveira, A.A.M. (2018). Design and analysis of a parallel hydraulic - pneumatic regenerative braking system for heavy-duty hybrid vehicles. Applied Energy, vol. 225, p. 60-77, D0l:10.1016/J.apenergy.2018.04.102.

[8] Zhao, L.J., Li, N., Fang, T. (2012). Simulation analysis of control strategy for TLT wheel coordination based on constant pressure network. Advanced Materials Research, vol. 591593 , p. 1962-1967, D0l:10.4028/www.scientific.net/ AMR.591-593.1962.

[9] Bender, F.A., Kaszynski, M., Sawodny, O. (2013). Drive cycle prediction and energy management optimization for hybrid hydraulic vehicles. IEEE Transactions on Vehicular Technology, vol. 62, no. 8, p. 3581-3592, D0l:10.1109/TVT.2013.2259645.

[10] Song, Y.P., Wang, W.T. (2014). Study on vehicle velocity controller for the energy regeneration system of the hydraulic hybrid vehicle. Advanced Materials Research, vol. 1051, p. 850-856, D0l:10.4028/www.scientific.net/AMR.1051.850.

[11] Chen, C.K., Vu, T.V., Hung, C.W., Lin, C.J. (2013). Modeling and simulation study of a series hydraulic hybrid vehicle. Applied Mechanics \& Materials, vol. 284-287, p. 834-838, D0l:10.4028/www.scientific.net/AMM.284-287.834.

[12] Chen, C.K., Vu, T.V., Hung, C.W. (2014). A simulation study of power management for a series hydraulic hybrid vehicle. In: Zelinka, I., Duy, V., Cha, J. (eds.) AETA 2013: Recent Advances in Electrical Engineering and Related Sciences. Lecture Notes in Electrical Engineering, Springer, Berlin, Heidelberg, vol. 282, p. 413-422, DOl:10.1007/978-3-642-41968-3_42.

[13] Chen, Z., Xiong, R., Wang, C., Cao, J. (2017). An on-line predictive energy management strategy for plug-in hybrid electric vehicles to counter the uncertain prediction of the driving cycle. Applied Energy, vol. 185, p. 1663-1672, DOI:10.1016/j.apenergy.2016.01.071.

[14] Zhou, L., Wang, G., Sun, K., Li, X. (2019). Trajectory tracking study of track vehicles based on model predictive control. Strojniški vestnik - Journal of Mechanical Engineering, vol. 65, no. 6, p. 329-342, DOl:10.5545/sv-jme.2019.5980.

[15] Ji, C., Zhu, Y., Liang, C, Liu, X. (2013). Simulation study on the operating characteristics of a hybrid hydraulic passenger car with a power split transmission. Vehicle System Dynamics, vol. 51, no. 10 , p. 1518-1532, Dol:10.1080/00423114.2013.812 223.
[16] Prater, G. Jr., Shahhosseini, A.M., Osborne, G.M., Zhang, S. (2010). Simulation studies for determining the response characteristics of a hydraulic hybrid powertrain subframe. International Journal of Heavy Vehicle Systems, vol. 17, no. 2, p. 99-118, D0I:10.1504/IJHVS.2010.033191.

[17] Baer, K., Ericson, L., Krus, P. (2018). Framework for simulationbased simultaneous system optimization for a series hydraulic hybrid vehicle. International Journal of Fluid Power, vol. 7, p. 1-13, DOI:10.1080/14399776.2018.1527122.

[18] Xi, P.Y., Chang, S.Q. (2010). Performance simulation and design of new series hydraulic hybrid bus. Applied Mechanics \& Materials, vol. 37-38, p. 866-869, D0l:10.4028/www. scientific.net/AMM.37-38.866.

[19] Li, Q., Chen, W., Li, Y., Liu, S., Huang, J. (2012). Energy management strategy for fuel cell/battery/ultra-capacitor hybrid vehicle based on fuzzy logic. International Journal of Electrical Power \& Energy Systems, vol. 43, no. 1, p. 514-525, DOI:10.1016/j.ijepes.2012.06.026.

[20] Trajkovski, J., Ambrož, M. (2018). The importance of friction coefficient between vehicle tyres and concrete safety barrier to vehicle rollover - FE analysis study. Strojniški vestnik Journal of Mechanical Engineering, vol. 64, no. 12, p. 753762, Dol:10.5545/sv-jme.2018.5290.

[21] Hegedüs, F., Bécsi, T., Aradi, S., Gáspár, P. (2019). Motion planning for highly automated road vehicles with a hybrid approach using nonlinear optimization and artificial neural networks. Strojniški vestnik - Journal of Mechanical Engineering, vol. 65 , no. 3, p. 148-160, D0l:/10.5545/svjme.2018.5802.

[22] Naseri, F., Farjah, E., Ghanbari, T. (2017). An efficient regenerative braking system based on battery/supercapacitor for electric, hybrid, and plug-in hybrid electric vehicles with BLDC motor. IEEE Transactions on Vehicular Technology, vol. 66, no. 5, p. 3724-3738, D0I:10.1109/TVT.2016.2611655.

[23] Held, M., Flärdh, 0., Mårtensson, J. (2019). Optimal speed control of a heavy-duty vehicle in urban driving. IEEE Transactions on Intelligent Transportation Systems, vol. 20, no. 4 p. 1562-1573, DOl:10.1109/TITS.2018.2853264.

[24] Denis, N., Dubois, M.R., Trovão, J.P.F., Desrochers, A. (2018). Power split strategy optimization of a plug-in parallel hybrid electric vehicle. IEEE Transactions on Vehicular Technology, vol. 67, no. 1, p. 315-326, D0l:10.1109/TVT.2017.2756049. 